\title{
José Lima Pedreira de Freitas e o redimensionamento e controle da doença de Chagas
}

\author{
José Lima Pedreira de Freitas and the redefinition \\ and control of Chagas disease
}

Juan Stuardo Yazlle Rocha ${ }^{1}$

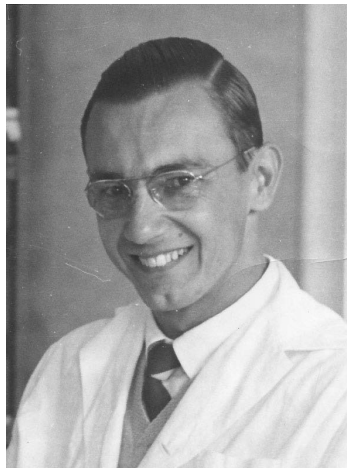

\begin{abstract}
A brief overview of the evolution of knowledge about Chagas disease since its discovery by Carlos Chagas in 1909 until the mid-1940s is presented. The trajectory of physician Pedreira de Freitas and his growing involvement in research in the area led to his contributions to laboratory diagnosis - which lent consistency and security to epidemiological surveys of Chagas disease - and the redefinition of the scale of the disease in Brazil and the Americas with its terrible social and economic impact. His proposal for the disease prevention model - based on selective purging in the application of insecticide - was adopted nationally and internationally and made it possible to bring the disease under control in Brazil and other countries. He devoted himself with equal intensity to enhancing the teaching of medical practices in the community and was a pioneer in the implementation of preventive medicine in medical education in Brazil.
\end{abstract}

Key words Prophylaxis for Chagas disease, Teaching preventive medicine, Pioneering preventive medicine
Resumo Apresenta-se brevemente a evolução do conhecimento acerca da Doença de Chagas, desde sua descoberta por Carlos Chagas em 1909 até meados dos anos 1940. A saga do médico Pedreira de Freitas e seu crescente envolvimento na pesquisa na área levaram suas contribuições para o diagnóstico laboratorial - que ofereceu segurança às pesquisas epidemiológicas da Doença de Chagas - e ao redimensionamento da doença no Brasil e nas Américas com seu terrível impacto social e econômico. A sua proposta do modelo de profilaxia - baseado no expurgo seletivo na aplicação de inseticida - foi adotado nacional e internacionalmente e permitiu controlar a doença no Brasil e em outros países. Dedicou-se com igual intensidade a renovar o ensino da prática médica na comunidade sendo pioneiro na implantação da medicina preventiva na educação médica no Brasil.

Palavras-chave Profilaxia Doença de Chagas, Ensino Medicina Preventiva, Pioneiro Medicina Preventiva
${ }^{1}$ Departamento de Medicina Social, Faculdade de Medicina de Ribeirão Preto, Universidade de São Paulo. Av. Bandeirantes 3900, Monte Alegre. 14049-900 Ribeirão Preto SP Brasil. juan.yazlle@gmail.com 


\section{Introdução}

Para compreender a importância do trabalho realizado pelo Professor José Lima Pedreira de Freitas temos que contextualizar seu trabalho na sua época, a de um Brasil que já desapareceu, em que nossas instituições e práticas eram muito diferentes das que temos hoje. Temos que conhecer também um pouco da história da Doença de Chagas, que ele conseguiu modificar com o impacto dos seus trabalhos. A história da Doença de Chagas nas Américas - e o conhecimento existente na patologia, na clínica, na epidemiologia e na profilaxia, bem como seu significado médicosocial - pelas varias fases porque passou nos mais de cem anos após a descoberta por Carlos Chagas em 1909 é analisada e comentada principalmente por Kropf ${ }^{1}$ em interessante e aprofundado trabalho sobre o processo pelo qual essa doença foi estabelecida e reconhecida como fato científico e uma questão de saúde pública; toma como eixo central o trabalho de Carlos Chagas e seus discípulos mais próximos no Instituto Oswaldo Cruz (RJ) e no Centro de Estudos e Profilaxia da moléstia de Chagas (CEPMC/IOC) em Bambuí, MG. Desde 1910, os enunciados sobre o quadro clínico e a importância médico social da nova enfermidade ensejaram o debate sobre as condições de atraso das regiões do interior do país, a relação entre endemias rurais e identidade nacional e o papel da ciência.

Coura $^{2}$ elaborou síntese sistematizada dos marcos das conquistas nos conhecimentos biológicos, clínicos e laboratoriais incorporando a contribuição de pesquisadores de outras muitas instituições e extensa revisão bibliográfica sobre o tema. Dias ${ }^{3}$, prolífico autor comenta a evolução dos conhecimentos e ações de combate à doença de Chagas nas primeiras décadas após sua descoberta, resgatando a relevante contribuição atuação de Emmanuel Dias, seu pai.

Desde que se apercebeu da gravidade da doença que descobrira (em 1909) e se inteirou de sua dimensão continental, Carlos Chagas nunca deixou de proclamar a urgência e a necessidade de seu controle. Já em 1910 e 1911, estabelecia ... que o maior impacto no enfrentamento da moléstia seria (pela) sua prevenção, estabelecendo como pontos mais vulneráveis o vetor domiciliado e a casa rural de má qualidade...

Chagas chegou a formular e a difundir a noção de que tal doença constituía o emblema dos males da nação brasileira (as endemias rurais) ${ }^{1}$. Os primeiros esforços - heroicos - no sentido de combater o vetor e, as primeiras experiências de laboratório para testar a eficácia de inseticidas sobre triatomíneos ocorreu em Belo Horizonte, entre 1920 e 1922, quando Ezequiel Dias, Samuel Libânio e Marques Lisbôa ensaiaram gás cianídrico, xilol, acetileno, creolina, querosene, naftalina, sulfureto de carbono e gases de carvão em pedra contra escorpiões e várias outras pragas domésticas (triatomíneos, baratas, percevejos, pulgas e ratos) ${ }^{3}$. Concluíram que o resultado era limitado e passageiro por não haver efeito residual.

Ainda que as descobertas de Carlos Chagas estivessem consolidadas na segunda década do século XX, surgiram muitas dúvidas e contestações acerca da gravidade e amplitude da doença, como a posição defendida por Afrânio Peixoto, segundo o qual essa moléstia não era importante e não causaria os problemas antevistos e temidos. Entre 1915 e 1923 houve proliferação de críticas tanto na Argentina como no Brasil, problema estudado por Kropf ${ }^{1}$.

"Como num círculo vicioso, o escasso número de casos enfraquecia a convicção sobre os enunciados clínicos sobre a doença, mas, justamente para que esse numero pudesse aumentar era fundamental que se impusesse algum grau de confiança em torno de critérios clínicos capazes de fazer os médicos suspeitarem de sua ocorrência e, pela localização do parasito ou pelo teste sorológico, firmarem o diagnóstico"1.

A situação começou a mudar em 1935 no Congresso Sanitário em Mendoza (Argentina), quando Cecilio Romaña descreve o sinal diagnóstico caracterizado por edema palpebral unilateral, inchaço no olho e na face atribuindo o fenômeno à porta de entrada da infecção (não pela picada mas pela contaminação com as fezes do triatomíneo) em 35 casos por ele estudados; três anos depois 300 casos agudos da doença são informados, baseados no "sinal do olho". Segundo François Delaporte "em um curto espaço de tempo a tripanossomíase americana alcançou uma amplitude sem precedentes. De doença rara, curiosidade patológica, ela se tornou uma afecção endêmica que era encontrada em todos os países da América do Sul"'.

Outro problema era a questão da possível relação etiológica entre a Doença de Chagas e o megaesôfago e megacólon endêmicos no Brasil, (que) vinha sendo debatida de longa data ... os trabalhos de Amorim e Correa Neto, Etzel, Correa Neto e Etzel (entre 1932 e 1934) demonstravam que o megaesôfago e o megacólon eram uma mesma doença ${ }^{4}$.

Até a década de 40 não se encontrara nenhum inseticida de ação residual suficientemente efetivo para combater um inseto de longa vida e enorme 
capacidade de jejum, que vive escondido em gretas e frestas da vivenda humana e de seu entorno, saindo na calada da noite, periodicamente, para realizar seu repasto em condições de pouca resistência das fontes alimentares e na exiguidade de inimigos naturais ${ }^{4}$.

Entre 1944 e 1946 autores ingleses na esteira (da busca) de inseticidas para combate à malária reestudam o hexaclorociclohexano (BHC ou Gammexane) que se mostrou altamente eficaz contra triatomíneos em laboratório. Em 1947 são realizados trabalhos pioneiros em zona endêmica - um no Brasil e outro na Argentina com bons resultados, direcionando a luta anti-chagásica. Emmauel Dias testou o BHC em Bambuí e depois em Uberaba (Triângulo Mineiro e cercanias $)^{4}$.

Foi neste cenário que o médico José Lima Pedreira de Freitas, aos 25 anos de idade inicia sua inserção profissional.

\section{Formação e trajetória profissional}

Nascido em 12 de janeiro de 1917, em Mococa, estado de São Paulo, era filho de José Pedreira de Freitas - médico, formado em Salvador (BA) e Dna. Alcina Lima Pedreira de Freitas, possuidor de uma fazenda na região de Arceburgo (MG), teve 6 irmãos. Fez o curso primário em escola particular e continuou sua formação na cidade de São Paulo, no Liceu Franco Brasileiro, no Colégio São Luiz e, no Colégio Universitário. Em 1936 ingressou no curso de Medicina da Faculdade de Medicina da Universidade de São Paulo onde recebeu o Prêmio Paulo Montenegro (melhor média de notas) no primeiro e no quarto ano. Concluiu o curso médico em 1941.

Depois de formado foi assistente voluntário encarregado de ministrar as aulas práticas sobre Semiologia do Aparelho Respiratório na Santa Casa de Misericórdia. Em 1943 dedicou-se ao Departamento de Parasitologia da Faculdade de Medicina da USP, dirigido na época pelo Prof. Augusto Leopoldo Ayrosa Galvão; com ele e mais o Dr. Mauro Pereira Barreto, vinha desenvolvendo estudos sobre malária e malarioterapia - de grande importância naquela época da Segunda Guerra Mundial; obteve bolsa do Fundo Universitário de Pesquisa para a Defesa Nacional (FUPD) e, em dois anos (1944-1945) publicou 5 trabalhos em parceria com Pereira Barreto sobre malária aviária.

Em 1944 a evolução dos conhecimentos sobre novos antimaláricos tornou sem interesse a procura de antimaláricos; por outro lado constatou a ne- cessidade de ampliar os conhecimentos a respeito do problema da moléstia de Chagas ${ }^{5}$. Em março de 1944 foi nomeado Assistente Extranumerário na Cadeira de Parasitologia da FMUSP e em dezembro daquele ano casou-se com Gilda Marcondes - em 1946 nasceu José Carlos o primeiro dos seus sete filhos. Em 1944 publicaria seu primeiro trabalho sobre a doença de Chagas - Alterações cardíacas na moléstia de Chagas.

Como relata no seu Memorial de concurso de Cátedra na FMRP-USP logo pôde concluir que o aperfeiçoamento dos métodos de diagnóstico constituía elemento indispensável para que pudessem ser desenvolvidos os estudos clínicos e epidemiológicos $^{6}$ pela dificuldade de encontrar o tripanossoma no sangue periférico de pacientes crónicos da doença de Chagas. Por isso, empenhou-se em desenvolver o diagnóstico sorológico da moléstia de Chagas para o qual contou com a colaboração inestimável do Dr. José Oliveira de Almeida - na época assistente do Departamento de Microbiologia e Imunologia da FMUSP. Embora enfrentasse inúmeras vicissitudes profissionais, (certamente a falta de efetivação na universidade devia fazer parte delas) persistiu em seu objetivo e em outubro de 1944 foi contratado segundo assistente substituto na cadeira de Parasitologia ${ }^{6}$.

Em setembro de 1947 foi nomeado assistente em comissão desta Cadeira, aí tendo permanecido até 1952, período em que participou intensamente do ensino teórico e do curso prático, sempre em regime de tempo integral exclusivo. Os principais resultados obtidos quanto ao aperfeiçoamento dos métodos de diagnóstico foram apresentados na tese de doutorado Contribuição para o estudo dos processos de laboratório para diagnóstico da molesta de Chagas. Defendida em 23 de outubro de 1947 na Cadeira de Parasitologia com distinção (grau 10,0). Naquela época a reação imunológica mais eficiente era a de fixação de complemento utilizando o antígeno aquoso ... A reação era dotada de grande sensibilidade e, principalmente, de especificidade em alto grau... sendo o maior inconveniente a instabilidade do antígeno... que perdia o poder fixador - havendo um tempo (útil) limite de 4 a 5 meses.

Visando particularmente o estudo da epidemiologia e da profilaxia da moléstia de Chagas, ainda em 1947, obteve a colaboração ... do Departamento de Saúde do Estado de S. Paulo, ... para instalar no distrito de Cássia dos Coqueiros, um Posto de Estudos da Moléstia de Chagas. Os principais resultados desse trabalho estão reunidos na publicação: Moléstia de Chagas, estudo clínico e epidemiológico ${ }^{6}$. 
Em 1949 publicou o trabalho lapidar que revolucionaria a percepção do problema social da Doença de Chagas ao permitir o diagnóstico individual dos casos crônicos e o conhecimento epidemiológico da extensão dessa enfermidade: "Nova técnica de fixação de complemento para a moléstia de Chagas - reação quantitativa com antígeno "gelificado" de culturas de Trypanossoma cruzi" , trabalho que serviu de base para seu concurso de docência-livre na Cadeira de Parasitologia com a tese "Reação de fixação de complemento para diagnóstico da moléstia de Chagas pela técnica quantitativa", aprofundando o estudo da reação praticada com o novo antígeno que descrevera com Almeida em 1949. O antígeno mantido em ampolas e com vácuo, ora a cerca de 10 graus $\mathrm{C}$, ora em temperatura ambiente, conservava suas propriedades pelo espaço de 3 anos, tempo máximo durante o qual se prolongou a observação do autor ${ }^{7}$.

Em 1954 quando transferiu-se à Faculdade de Medicina de Ribeirão Preto conseguiu instituir como rotina o exame sorológico de Machado \& Guerreiro e de Wassermann nos pacientes novos registrados no Hospital das Clínicas da FMRP para detectar a doença de Chagas e a sífilis.

\section{A produção científica}

A transferência de Pedreira à Faculdade de Medicina de Ribeirão Preto, com o regime de trabalho de dedicação integral à docência e à pesquisa, propiciou-lhe um estimulante ambiente científico e contato com importantes pesquisadores. "A nova e moderna Faculdade de Medicina de Ribeirão Preto, no interior de São Paulo, congregou um notável grupo de pesquisa em doença de Chagas, o qual criou, como modelo epidemiológico e de controle de vetores, em Cássia dos Coqueiros ${ }^{5,8,9}$, uma nova linha de estudos ecológicos de reservatórios e vetores, desenvolvendo técnicas sorológicas originais ${ }^{8,9}$ bem como inéditos estudos clínicos e epidemiológicos ${ }^{10} \mathrm{e}$ de patogenia e patologia da doença de Chagas ${ }^{2,11-13}$.

Em uma década publicou aproximadamente 36 trabalhos sobre diversos aspectos da doença de Chagas: diagnóstico laboratorial, a clínica, prevalência em populações, transmissão intrauterina, combate aos triatomíneos, transmissão acidental, esterilização do sangue contaminado em bancos de sangue, infecção chagásica em animais domésticos, sobre o xenodiagnóstico ampliando e aprofundando o conhecimento acerca da Doença de Chagas.
Pedreira de Freitas tornou-se autoridade na Doença de Chagas, internacionalmente reconhecido pelos estudos realizados e, sobretudo, pela amplitude e profundidade do seu conhecimento da endemia chagásica. A possibilidade de fazer com segurança o diagnóstico de pessoas infectadas muito tempo antes - os chagásicos crônicos, praticamente sem tripanossomas circulantes permitiu a associação da doença de Chagas com o desenvolvimento dos "megas" nas pesquisas realizadas por Fritz Koeberle. Embora os dados clínicos, epidemiológicos e sorológicos não (deixassem) dúvida quanto à relação etiológica entre a doença de Chagas e o megaesôfago e megacólon endêmicos ... restava provar que aquelas lesões eram primitivas e a dilatação secundária e que as mesmas eram produzidas pela infecção por Trypanosoma cruzi ${ }^{4}$. Tinha-se a ideia, na época, de que seria indispensável o achado do parasita nas paredes do esôfago e do cólon dilatados para a comprovação anatomopatológica da etiologia chagásica. Por esta razão, Fritz Koeberle, patologista austríaco, docente na FMRP-USP "compreendeu que o achado do parasito no órgão comprometido não era a questão principal". "O fundamental era demonstrar que as formações megálicas são sequelas do processo infeccioso, às quais chamava de patias chagásicas, ao contrário de nósos, a infecção em si”"4. A reação sorológica de Machado e Guerreiro, com o antígeno gelificado aceita como prova diagnóstica dos pacientes chagásicos crônicos, seria o elo que faltava para "examinar todos os esôfagos de chagásicos crônicos autopsiados" e ligar o "megas" com a infecção pelo tripanossomo.

Neste novo cenário, as contribuições propiciadas pelos estudos de Pedreira de Freitas e Koeberle em Ribeirão Preto trazem à cena o terrível impacto social e econômico causado pelo mal de

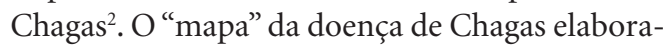
do por Pedreira de Freitas para uma reunião de especialistas da OPAS/OMS em Washington em março de 1960 impactou autoridades sanitárias nacionais e internacionais e dominou a visão sobre o problema, como o demonstra a sua reprodução no livro clássico de Veronesi ${ }^{14}$ sobre Doenças Infecciosas e Parasitarias na sua edição de $1991-25$ anos após a morte do autor (Figura 1).

Em março de 1960, em reunião do Comitê de Especialistas na Doença de Chagas realizada em Washington, EUA, sob auspícios da Organização Panamericana da Saúde, Pedreira de Freitas chama a atenção para a extensa disseminação de triatomíneos na América Latina, principalmente de espécies adaptadas aos domicílios, importantes vetores na transmissão do Tripanosoma cruzi. 


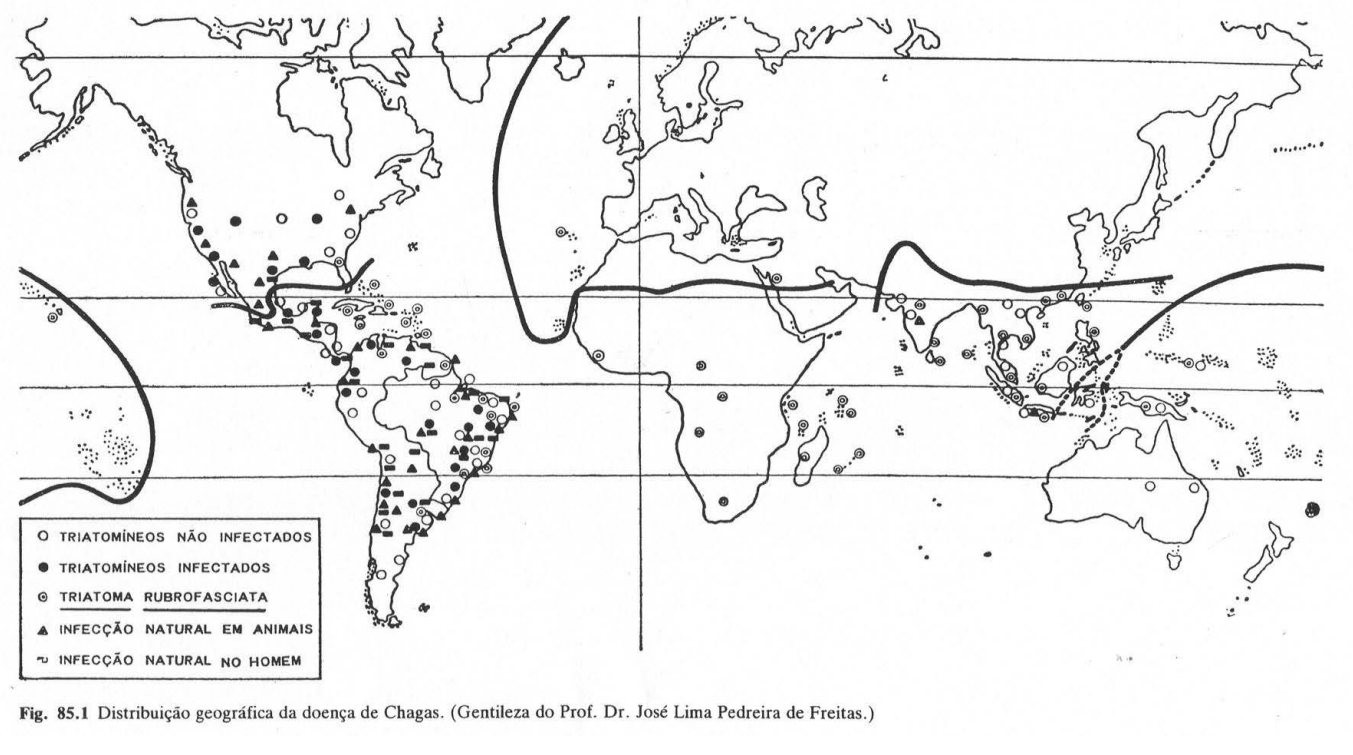

Figura 1. Mapa da Doença de Chagas extraído do capítulo "Doença de Chagas”"14.

Apontou, então, para dois fatos contraditórios na luta contra a doença de Chagas: de um lado os bons resultados obtidos com o uso de inseticidas de poder residual no combate aos triatomíneos e de outro os poucos países com programas extensos de profilaxia e, mesmo nestes, a pequena escala em comparação com a "magnitude do problema revelada pela prevalência, morbidade e mortalidade por essa infecção"'. Mesmo naqueles que reconhecem a magnitude do problema... a dificuldade para a generalização do combate a esses insetos tem residido em dois fatos fundamentais: de um lado, a grande extensão das áreas do continente americano onde... 35 milhões de indivíduos moram em casas infestadas por triatomineos ... necessitando-se o expurgo de cerca de 5 milhões delas. De outro lado, a necessidade de que esse combate seja mantido por prazo longo porquanto se trata de parasitose na qual não somente o vetor é autóctone, como também o são os reservatórios vertebrados que, .... se mantém infectados e infectantes por dezenas de anos.... Acrescentou Pedreira que, embora nenhum dos inseticidas empregados até então pudesse ser considerado ideal ... os resultados com eles obtidos servem para basear o combate aos triatomíneos ao serem aplicados nos domicílios e peridomicilios. Problema em aberto permanece, contudo, o do ritmo ou intervalos das aplicações. Somente um melhor conhecimento da biologia dos vetores do T. cruzi poderá fornecer elementos para que seu combate possa se fazer de maneira mais duradoura, eficaz e envolvendo despesas compativeis com os recursos de que podem dispor as áreas de menor desenvolvimento onde justamente a endemia chagásica constitui maior problema ${ }^{15}$.

$\mathrm{Na}$ sua tese para o concurso de cátedra na Faculdade de Medicina de Ribeirão Preto, síntese de trabalho realizado ao longo de 6 anos (entre 1957 e 1963), Pedreira refere que trata-se de um "trabalho condicionado pelas informações obtidas através do estudo da biologia dos triatomíneos ... o que permitiu equacionar a aplicação de inseticidas segundo normas que diferem até certo ponto daquelas que vem sendo habitualmente usadas... e que o método preconizado poderá permitir sensivel economia tornando-o particularmente indicado para as condições da época. Preocupado com os efeitos nocivos dos inseticidas fosforados ou clorados, escolhidos pelo seu poder residual, alerta para os problemas do seu uso, já denunciados por Rachel Carson no livro "Silent Spring" - mormente por se tratar de inseticidas que terão de ser aplicados no interior de domicílio humano onde os moradores ficarão sujeitos a contato intimo e prolongado com esses tóxicos. Conclui na apresentação da tese que a solução do dilema pode vir do conhecimento de como se faz a reinfestação das casas pelos triatomíneos de hábitos domiciliários ${ }^{15}$. 
Na tese fez extensa revisão dos trabalhos existentes à época sobre as modalidades de combate, com diferentes inseticidas e dosagens bem como sob os métodos de aplicação e destaca a proposta de E. Dias de rociar os domicílios e repetir a ação 30 dias depois - embora ele mesmo tivesse detectado a persistência da reinfestação em 6\% dos casos. O desenvolvimento do seu projeto de construção de um novo modelo de profilaxia da doença de Chagas é uma síntese do professor, pesquisador, parasitologista, médico, sanitarista, educador, ator social e líder de equipe de acadêmicos e técnicos, articulador com livre transito nos órgãos oficiais de saúde pública, admirado pela sua lealdade e solidariedade. Eram seus assistentes àquela época (1963) os docentes Geraldo García Duarte, Nagib Haddad, Clarisse D. Gardony Carvalheiro, José Romero Teruel e Manildo Fávero e os técnicos em Cássia dos Coqueiros João Albertim e Teotonio Sabino Soares.

Trabalhou com a população de Cássia dos Coqueiros desde 1945 e conquistou o apoio e a colaboração de todos que solicitavam rociar novamente seus domicílios mesmo depois da mortandade de galinhas e gatos observada após a primeira aplicação de inseticidas. Conheceu e classificou as características dos domicílios e das dependências mais comuns: galinheiros, chiqueiros, paióis, etc. Pesquisou os habitats extradomiciliários naturais de inúmeros insetos, com a colaboração de moradores. Dividiu as 563 moradias do município em dois grupos comparáveis que receberiam aplicações/rociados de BHC (286) e Dieldrin (277) com os 3 tipos de moradias, pau-apique (140), de tijolos ( 401), de madeira e outros materiais (22). Antes de aplicar o rociado experimental pesquisou a infestação aplicando pó de piretro nas frestas e brechas das construções para desalojar os insetos, obtendo assim o número de casas infestadas, e os triatomíneos encontrados bem como o número de domicílios pesquisados por capturador. Além disso, construiu 6 casas de pau-a-pique experimentais, barreadas, situadas em áreas de pasto ou capão de mato onde colocou galinhas para atrair os insetos, tomando o cuidado de acender um lampião à noite para simular a habitação, procedimento que se estendeu durante 101 e 129 noites entre 1959 e 1961.

O conteúdo intestinal dos triatomíneos capturados passou por um teste de precipitinas com soros anti-homem, cão, gato, galinha, porco, boi, cavalo, rato, gambá, tatu e morcego para conhecer o hábito alimentar dos insetos. A aplicação do inseticida seguiu um esquema operacional bem planejado e controlado - número de casas por aplicador, tempo gasto, etc. Testou repasses de inseticidas com 15 dias, 1 a 2 meses, 3 a 6 meses e 12 meses. Descartou o Dieldrin pela sua baixa eficiência e pelos melhores resultados com o BHC. Descobriu que a reinfestação estava associada ao nomadismo dos moradores e era muito menor entre sitiantes e maior nas colônias das fazendas; confirmou o conceito dos nichos - criadouros naturais de insetos, situados geralmente perto da sua fonte de alimentação, comprovado pelo teste de precipitinas, e a baixa tendência à migração dos insetos.

Preconizou a associação das ações de erradicação da malária com a profilaxia da doença de Chagas. Ao expurgo sistemático ou total prescreveu as revisões periódicas e os expurgos seletivos dos focos residuais diminuindo os custos e aumentado o rendimento do trabalho. Destacou que os sucessivos repasses produziam um efeito de educação sanitária na população.

\section{O professor}

Duas características da criação da Faculdade de Medicina de Ribeirão Preto da USP a fariam destacar-se entre as escolas médicas brasileiras: a ênfase no binômio ensino-pesquisa, com a educação médica centrada na atividade de investigação laboratorial e clínica e o regime de trabalho preferencial do corpo docente de dedicação em tempo integral à docência e à pesquisa. Esta característica inovadora viria a ser complementada pela introdução de disciplinas como a Psicologia Médica, a Higiene e Medicina Preventiva (HMP), nesta ultima incluído o ensino da Bioestatística. A HMP era uma nova tendência nos EUA, tentativa de corrigir e compensar as distorções resultantes da excessiva multiplicação de especialidades. Tentar reintegrar o homem, promovendo a visão holística do individuo e sua compreensão ao interior da família e comunidade, incutindo no futuro médico a mentalidade da prevenção, em seus diversos níveis, era o objetivo do projeto preventivista ${ }^{16}$. Não seria uma nova especialidade médica, mas tratava de promover uma atitude diante da saúde-doença, revelando ser um projeto político-ideológico com uma concepção particular dos problemas médico-sociais ${ }^{17}$. Naquela época não existia no Brasil a excessiva tendência à multiplicação de especialidades na formação médica, problema hoje existente - mas promover a prevenção era, e ainda é, muito importante.

As ideias de Pedreira acerca do ensino médico, direcionadas inicialmente para a área da parasi- 
tologia, foram fortalecidas com o apoio da Fundação Rockfeller em 1952 para fazer o curso de Saúde Pública em John Hopkins e visitar varias instituições como o National Health Institute, o Army Medical Center, o Department of Health (New York).

Em setembro de 1953 Pedreira foi contratado pela Faculdade de Medicina de Ribeirão Preto da USP como Professor Adjunto do Departamento de Parasitologia e em 18 de agosto de 1954 assumiu como Professor Catedrático de Higiene, convidado para instalar o o primeiro Departamento de Higiene e Medicina Preventiva no Brasil. Naquele momento o autor estava já convencido da necessidade de que os aspectos preventivos e sociais da medicina deveriam ser apresentados aos futuros médicos não como uma especialidade, mas como um ponto de vista constituindo parte integrante de sua formaçãa $o^{16}$. A maneira como deveria ser focalizado o ensino da HMP foi consolidada na visita a Departamentos semelhantes nos EUA e Porto Rico onde se iniciava um extenso programa de seguimento de famílias e outros onde se desenvolvia o "interdepartmental teaching program".

Criado o Departamento de Higiene e Medicina Preventiva na Faculdade de Medicina de Ribeirão Preto, em 1955, iniciou o ensino de graduação; as atividades didáticas consistiam numa disciplina de Bioestatística, que acabaria se fixando no primeiro ano do curso médico, a disciplina de Epidemiologia e Profilaxia das Doenças Transmissíveis - articulada com o curso de doenças infecciosas e parasitárias do Departamento de Clínica Médica, oferecida aos alunos do quarto ano médico. No ano seguinte teve início o Serviço de Assistência Médica Preventiva e Social a Famílias com o objetivo de promover a integração de atividades clínicas com outros Departamentos da FMRP e Serviços da Secretaria de Saúde, em especial os Dispensários da Lepra e Tuberculose, a Delegacia de Saúde e o Centro de Saúde de Ribeirão Preto, além de oferecer assistência à população assistida. Em 1957 iniciou-se a colaboração com o Departamento de Pediatria, ambos participando conjuntamente do planejamento e execução do Programa de Visitas Domiciliarias. Colaborou com o ambulatório de Pediatria e assumiu o Serviço de Imunizações do Hospital das Clínicas. Em 1959 foi iniciado o estágio de Medicina Preventiva oferecido a grupos de 10 alunos no quarto ano médico, enquanto o ensino teórico de epidemiologia e profilaxia foi integrado às aulas teóricas de Clínica Médica e Cirurgia no então chamado Curso Conjunto, bienal, oferecido aos alunos do quarto e quinto ano sobre as enfermidades mais prevalentes no país.
Pedreira expôs seu pensamento acerca do ensino em uma Conferência sobre o Ensino de Medicina Preventiva e Social no Primeiro Seminário Centro-Americano de Educação Médica em Tegucigalpa (Honduras) em maio de 1961 na qualidade de Assessor da OMS/OPAS ${ }^{17}$. Nesta Conferência, mais do que conhecimentos ou conteúdos práticos ele apresentou e discutiu as suas convicções a respeito de como deveria ser o ensino oferecido a futuros médicos. Assinalou que já naquela época havia diferenças entre autores acerca do que era a HMPS e baseou-se para sua exposição nas suas vivências nas Conferências de "Preventive Medicine in Medical Schools" (Colorado Springs, USA, 1952), "First World Conference on Medical Education” (London, UK, 1953), "Seminários sobre Enseñanza de Medicina Preventiva de Viña del Mar” (Chile, 1955) e Tehuacán (México, 1956) - que contribuíram decisivamente para a aceitação, praticamente pela totalidade das escolas de medicina da America Latina deste novo conceito do ensino da medicina preventiva ${ }^{17,18}$.

A meta da educação médica seria formar profissionais generalistas, capazes de empreender o exercício da profissão e acompanhar os avanços da medicina. Considerava que os setores fundamentais da HMPS eram a medicina preventiva, a medicina social, a saúde pública e a estatística - incluindo aí a estatística vital. Entendia a medicina preventiva na concepção de Hugh Leavell e que se deveria demonstrar ao futuro médico que a prevenção pode e deve ser exercida nos cinco níveis sistematizados por aquele autor (promoção da saúde, prevenção específica, diagnóstico precoce, tratamento e reabilitação). Os avanços da medicina curativa levaram ao "divorcio" entre a clínica e a preventiva - "relegada esta última ao isolamento de uma especialidade de menor importância" relacionada à saúde pública enquanto as especialidades médicas ocupavam o ideário profissional. As conferências e os seminários antes citados foram um esforço para corrigir aquela distorção. Pedreira de Freitas acreditava que para alcançar os objetivos do ensino da HMPS não era necessário oferecer um conjunto de disciplinas, mas incutir precocemente nos futuros médicos o valor da prevenção em estreita relação com a clínica médica, pediatria e obstetrícia. Enxergava que no trabalho nos hospitais, ambulatórios e junto às famílias haviam muitas oportunidades para o ensino da prevenção e para a difusão desses conhecimentos.

Na Medicina Social se deveria procurar considerar os problemas de saúde e enfermidades dos indivíduos em relação à sociedade onde vi- 
vem, começando no núcleo básico da sociedade, a família; também levar em conta a relação do individuo com seus semelhantes e as implicações sociais dos problemas médicos - considerando os aspectos ecológicos e inclusive econômicos da medicina. Uma maneira muito natural e lógica de apresentar aos futuros médicos os aspectos preventivos e sociais da medicina será (escrevia ele) através do estudo da história natural das enfermidades analisando os elementos que constituem a estrutura epidemiológica que determina as diferentes condições de saúde e doença.

A partir de 1964 o Posto Médico do Município de Cássia dos Coqueiros - destinado a promover estudos sobre a Moléstia de Chagas, foi transformado em Posto Médico Rural da FMRP servindo de campo de estágio a alunos do sexto ano e médicos residentes do HC-FMRP no chamado Estágio Rural e, em 1966, foi inaugurado o novo Posto Médico do DHMP - que o Prof. Pedreira não chegou a conhecer pois encontrava-se hospitalizado por acidente automobilístico no retorno a Ribeirão Preto vindo de consultoria no exterior. Vitima do acidente automobilístico, o Prof. Pedreira veio a falecer em 15/06/1966 aos 49 anos de idade. Em 1970, o Posto Médico Rural da FMRP seria transformado no Centro Médico Social Comunitário Pedreira de Freitas.

Muitas homenagens recebeu Pedreira de Freitas, mas destacamos a que ocorreu em sessão especial na Organização Pan Americana da Saúde (OPAS) e da Fundação Panamericana da Saúde (PAHEF), em Washington, em 30/09/2013 ${ }^{19}$ :
El médico Jose Lima Pedreira de Freitas fue homenageado postumamente hoy como ganador del Premio Sergio Arouca 2013 a la Excelencia en Atención Sanitaria Universal por su rol clave en el desarrollo de la salud pública en Brasil... el premio reconoce el impacto del Dr. Pedreira de Freitas en los jóvenes profesionales de la salud así como en los programas que afectan la medicina social y comunitária.

El Dr. Carlos Alberto Pedreira de Freitas, Pediatra y Doctor en Salud Pública, quien aceptó el premio en nombre de su padre, dijo: "Siento que este homenaje daría a mi padre un sentimiento de logro, no tanto por la distinción, que sin duda apreciaría, sino por la oportunidad de compartir con sus compañeros el entusiasmo que el premio generaría. Sobre todo porque el mismo profesor Arouca fue motivado por mi padre para encaminarse hacia la salud pública y la medicina preventiva. El profesor Arouca una vez dijo 'Gracias a la gran influencia de un maestro carismático llamado José Lima Pedreira de Freitas, he desarrollado una pasión por la medicina preventiva'.

$\mathrm{Na}$ acepção do termo, professor não é apenas quem transmite conhecimentos sedimentados em livros, mas também quem professa - quem é convicto, adepto e divulga publicamente uma crença com a qual está comprometido e Pedreira era Professor na acepção plena do termo.

É possível conhecer outros aspectos da personalidade de Pedreira de Freitas, recorrendo a depoimentos e registros de colegas e colaboradores em Passos $^{18}$, PAHO Foundation ${ }^{19}$, IPTV USP ${ }^{20} \mathrm{e}$ Esteto $^{21}$. 


\section{Referências}

1. Kropf SP. Doença de Chagas, doença do Brasil: ciência, saúde e nação (1909-1962) [tese]. Niterói: Universidade Federal Fluminense; 2006.

2. Coura JR. Síntese histórica e evolução dos conhecimentos sobre a doença de chagas. In: Coura JR. Clínica e terapêutica da doença de Chagas: uma abordagem prática para o clínico geral. Rio de Janeiro. Editora Fiocruz; 1997.

3. Dias JCP. Os primórdios do controle da doença de Chagas (em homenagem a Emmanuel Dias, pioneiro do controle, no centenário de seu nascimento). Rev. Soc. Bras. Med. Trop. 2011; 44(Supl. II):12-18.

4. Rezende JM. Fritz Koeberle e seus estudos sobre a Doença de Chagas. In: Rezende JM. À Sombra do Plátano Crônicas da história da Medicina. São Paulo: Editora Unifesp; 2009.

5. Freitas JLP. Inquérito preliminar sobre doença de Chagas no município de Cajuru, Estado de São Paulo. Hospital 1946; 29:155-165.

6. Pedreira de Freitas JL. Memorial - Concurso Professor Catedrático de Higiene e Medicina Preventiva. Ribeirão Preto: USP; 1963.

7. Freitas JLP, Almeida JO. Nova técnica de fixação de complemento para moléstia de Chagas - Reação quantitativa com antígeno "gelificado" de culturas de Tripanossoma cruzi. Hospital 1949; 25:787-800.

8. Freitas JLP, Ferreira DA, García G, Haddad N. Resultados do combate intensivo dos triatomíneos domiciliares em uma área restrita no estado de São Paulo (Distrito de Cássia dos Coqueiros, município de Caju$\mathrm{ru})$. Anais do Congresso Internacional sobre a Doença de Chagas. Rio de Janeiro; 2:543-569; 1959.

9. Freitas JLP, Siqueira AF, Ferreira OA. 1959b Investigações epidemiológicas sobre triatomíneos de hábitos domésticos e silvestres com auxilio da reação de precipitina. Anais do Congresso Internacional sobre a Doença de Chagas. Rio de Janeiro, 2:525-556 in: Coura, JR ibidem.

10. Ramos J, Freitas JLP, Borges S. Moléstia de Chagas. Estudo clínico e epidemiológico. Arquivos Brasileiros de Cardiologia 1949; 2:111-162.

11. Koberle F. Patogenia da moléstia de Chagas. Rev Goiana de Medicina 1957; 3:155-180.

12. Koberle F. Moléstia de Chagas - Enfermidade do sistema nervoso. Anais do Congresso Internacional sobre a Doença de Chagas. Rio de Janeiro; 2:691-716; 1959.

13. Koeberle F. Patogenia do megaesôfago brasileiro e europeu [tese]. Ribeirão Preto: USP; 1962.
14. Veronesi R. Doenças Infecciosas e Parasitárias. $8^{\mathrm{a}}$ ed. Rio de Janeiro: Guanabara Koogan SA; 1991.

15. Freitas JLP. Importância do expurgo seletivo dos domicílios para a profilaxia da Moléstia de Chagas pelo combate aos triatomíneos [tese]. Ribeirão Preto: USP; 1963.

16. Rocha JSY Ruffino Netto A Nogueira JL. 40 Anos da FMRP- USP. O Departamento de Medicina Social. Rev. Medicina Ribeirão Preto 1992; 35(3):74-84.

17. Pedreira de Freitas JL. La enseñanza de la medicina preventiva y social. Conferencia en El Primer Seminário Centro-Americano de Educación Médica (Tegucigalpa, Honduras). 1961. In: Passos ADC, organizador. Medicina Social na Faculdade de Medicina de Ribeirão Preto da Universidade de São Paulo - 1954 a 2014. Ribeirão Preto: Holos Editora; 2014. p. 19-24.

18. Passos ADC, organizador. Medicina Social na Faculdade de Medicina de Ribeirão Preto da Universidade de São Paulo - 1954 a 2014. Ribeirão Preto: Holos Editora; 2014.

19. PAHO Foundation. La OPS y PAHEF galardonan com premio póstumo a distinguido professor de Brasil. [acessado 2016 jan 25]. Disponível em: http://www. pahofoundation.org/es/news/132-news/2013/383paho-and-pahef-posthumously-award-distinguished -professor-from-brazil.html

20. Vídeo institucional sobre o trabalho de José Lima Pedreira de Freitas produzido em 2010 pelo DMS-FMRP-USP por ocasião dos 100 anos da Doença de Chagas. [acessado 2016 jan 25]. Disponível em: http://iptv.usp. $\mathrm{br} /$ portal/video.action?idItem $=27446$

21. O Esteto em revista. (Suplemento Especial do Jornal) (1966) dos alunos da FMRP-USP por ocasião do falecimento de Pedreira de Freitas. [acessado 2016 jan 25]. Disponível em: http://rms.fmrp.usp.br/upload/ file/O_Esteto_1966.pdf

Artigo apresentado em 27/01/2016

Aprovado em 12/03/2016

Versão final apresentada em 15/03/2016 
